\begin{tabular}{|c|c|}
\hline 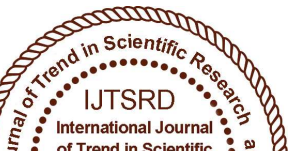 & $\begin{array}{l}\text { International Journal of Trend in Scientific } \\
\text { Research and Development (IJTSRD) }\end{array}$ \\
\hline $\begin{array}{lll} & \\
0\end{array}$ & International Open Access Journal \\
\hline 000 & ISSN No: $2456-6470 \mid$ www.ijtsrd.com | Volume - 2 | Issue -4 \\
\hline
\end{tabular}

\title{
Mechanical Characterization of Hybrid Fiber Reinforced Composite
}

\author{
M. Palpandi ${ }^{1}$, T. Ramakrishnan ${ }^{2}$, T. Rajkumar ${ }^{3}$ \\ ${ }^{1,2}$ Assistant Professor, Department of Mechanical Engineering, \\ ${ }^{1,2}$ PSNA College of Engineering and Technology, Dindigul, Tamil Nadu, India \\ ${ }^{3}$ Assistant Professor, Department of Mechanical Engineering, \\ ${ }^{3}$ K.Ramakrishnan College of Technology, Trichy, Tamil Nadu, India
}

\section{ABSTRACT}

Natural fiber is mostly used in automobile and aerospace industry. Currently most used in natural fiber reinforcement are sisal, flex, hemp, and banana. The natural fiber is mined by using manual and retting processes. The agricultural waste can be used to prepare fibers it has major advantage is renewable resources and have marketing demand. The polymer composite have many advantage such as mechanical strength such as tensile, impact and flexural strength over traditional glass fiber and monogenic materials. In this paper to fabricate the polymer composite with using on sisal and banana reinforcement with treated with NAOH solution. These processes are enhancing the bonding strength between fiber and resin by removing moisture contents. After fabricated polymer composite to prepare the samples as per ASTM standard, the samples are tested for different composition of sisal, banana and sisal banana reinforced composites.

Keywords: fiber hybrid, mechanical properties, banana, sisal fiber

\section{INTRODUCTION}

Polymer composite are widely used in aerospace, automotive, sport equipment etc. now a days all industries need in friendly environments, economic and ecological reasons in polymer matrix composite[1-3]. The human history 3000 years ago clay reinforcement based polymer matrix composite in ancient Egyptians building construction. In present year the polymer composite are developed in lighter weight, Cost effective, performance oriented, excellent mechanical strength, and high corrosion resistance, Dimensionally stable and also suitable for several applications[4-6]. The polymer composite materials produce the specific application and enhancing resins performance, and also improve the mechanical properties such as tensile, impact, hardness, and flexural strength[7-11]. Fiber is a reinforcement of polymer matrix composite such as banana fiber, sisal fiber etc. the reinforcement also improve the properties of the polymer composite [1115]. Deferent types of fabrication techniques and Treatment are used to fabricate the composite such as Sodium Lauryl Sulfate Treatment [16]. In this types of fabrication method and treatments are using improve the wear and mechanical behavior [17-20].

In this paper used id in synthetic fiber. Banana fiber, sisal fiber and sisal and banana type fabricate the total $15 \%$ of reinforcements. The application of polymer composite is lamp shades, wall covers, curtains, upholsteries, etc. sisal type polymer used to make the twin and rope. The main advantage of sisal type composites is strong, stable and versatile material. The Decortication process is used to apply the extracted from the fiber. So many advantage of sisal type polymer composite because environmentally friendly strengthening agent to replace asbestos and 
fiber glass in composite materials in various uses including the automobile industry.

\section{MATERIALS AND METHODS}

\section{1 sisal fiber}

Sisal is one types of natural is exceptionally durable and a low maintenance with minimal wear and tear strength compare to other type of fiber. The main application of sisal type composite is to make the rope and twine type products.

\subsection{Banana Fiber}

Banana fiber is oldest cultivated plants. From table 1 and table 2 shows the chemical composition and physical properties of banana and sisal type fiber respectively.

Table 1. Composition of Sisal and Banana Fiber

\begin{tabular}{|c|c|c|c|}
\hline SL.NO & Composition & Sisal & Banana \\
\hline 1 & Cellulose $\%$ & 66 & 63 \\
\hline 2 & Hemicellulose $\%$ & 9 & 17 \\
\hline 3 & Lignin $\%$ & 8.5 & 6 \\
\hline 4 & Moisture content $\%$ & 9 & 10.5 \\
\hline
\end{tabular}

Table 2. Properties of Banana and Sisal Fiber

\begin{tabular}{|l|l|l|l|l|l|l|l|l|}
\hline Fiber & Diameter & $\begin{array}{l}\text { Density } \\
(\mathrm{Kg} / \mathrm{m} 3\end{array}$ & $\begin{array}{l}\text { Tensile } \\
\text { strength } \\
\mathrm{(MPa})\end{array}$ & $\begin{array}{l}\text { Tensile } \\
\text { modulus } \\
(\mathrm{GPa})\end{array}$ & $\begin{array}{l}\text { Elongation } \\
\text { at break (\%) }\end{array}$ & $\begin{array}{l}\text { Flexural } \\
\text { modulus } \\
(\mathrm{GPa})\end{array}$ & $\begin{array}{l}\text { Lumen } \\
\text { size }\end{array}$ & $\begin{array}{l}\text { Micro } \\
\text { fibrillar } \\
\text { angle }\end{array}$ \\
\hline Sisal fiber & 200 & 1350 & 320 & 11.5 & 6 & 13 & 10 & 10 \\
\hline $\begin{array}{l}\text { Banana } \\
\text { fiber }\end{array}$ & 118 & 1250 & 520 tern & 180 nal & 4 Urnal & 4 & 5 & 10 \\
\hline
\end{tabular}

\subsection{Chemical Treatment}

The production of natural fiber is used to sodium hydroxide (NAOH). The NAOH are used to treatment of bleaching and cleaning the surface of natural fiber to produce high-quality fiber. Distilled water and 5\% NAOH solution was prepared using sodium hydroxide pellets. The increase in $\mathrm{NAOH}$ to affects the fiber properties by reducing the bonding capacity during preparation of composites. The Fibers are then dipped in the solution for $2 \mathrm{hrs}$ separately. Then it is washed with running water. It is then kept in hot air oven for 3 hours at $80^{\circ} \mathrm{C}$.

\subsection{Banana Fiber Extraction}

The banana is cut from $500 \mathrm{~mm}$ shied in 4 pieces leaner each was totally submerged in water for 15 days. The stems from banana plants (Musa paradisiacal) should be kept in dry air.

\subsection{Extraction Process of Sisal Fiber}

The retting processes are used to extract the Sisal fiber. It's used to improve the Boiling and Mechanical extraction methods and also in this process include the "Rador machine". The extraction process is done by using manually. In manual process used in knife edge. In knife edge used to remove the pith of the sisal leaf.

\section{EXPERIMENTAL METHODS}

\subsection{Pattern}

The ASTM D37-08 standard is using design the pattern. The pattern material is mild steel and dimension of the pattern size is $235 \times 85 \times 15 \mathrm{~mm}$. The figure 1 shows the pattern and experimental technique using composite material.

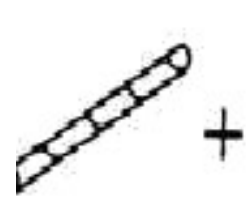

Fiber

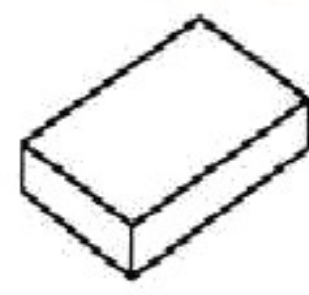

Resion

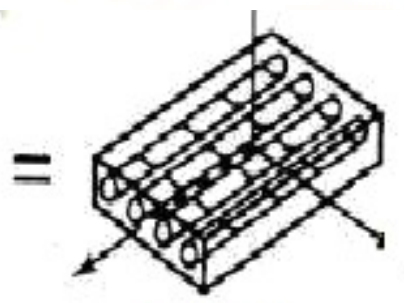

composite material 


\subsection{Mould Preparation}

10:1 ratio is using epoxy resin LY556 and hardener (HY951) is mixed in a ratio. The $250 \mathrm{~g}$ weight percentage of fiber used. The combination of resin, sisal and banana to fabricate the polymer composite. It can pressed in a hydraulic press at the temperature of $120^{\circ} \mathrm{C}$ at 30 minutes and a pressure of $35 \mathrm{~kg} / \mathrm{cm} 2$ for 45 minutes is applied before it is removed from the mold.

\subsection{Composition of Resin and Natural Fiber}

In This paper prepare the $65 \%$ of epoxy resin maintain and remaining percentage of reinforcement to add the sisal and banana fiber. From table 3 shows the different weight percentage of reinforcement to add the epoxy resin.

Table 3 percentage variation of sisal and banana fiber

\begin{tabular}{|l|l|l|l|}
\hline $\begin{array}{l}\text { \% of Banana } \\
\text { fiber }\end{array}$ & $\begin{array}{l}\text { \% of sisal } \\
\text { fiber }\end{array}$ & $\begin{array}{l}\text { \% of epoxy } \\
\text { resin }\end{array}$ & \begin{tabular}{l} 
Total \% \\
\hline 17.5
\end{tabular} \\
\hline 17.5 & 65 & 100 \\
\hline 17.5 & 17.5 & 65 & 100 \\
\hline 35 & 0 & 65 & 100 \\
\hline 0 & 35 & 65 & 100 and \\
\hline
\end{tabular}

\section{RESULTS \& DISCUSSIONS}

\section{1 flexural tests}

Flexural strength or bending strength to apply the point load at centre of the specimen. the ASTM D790 are using flexural strength and specimen dimension is $125 \times 12.7 \mathrm{~mm}$. and cross head speed of $10 \mathrm{~mm} / \mathrm{min}$. the figure 2 shows the ASTM standard specimen and figure 3 shows the after flexural strength value. Figure 4 clear shows the variation of flexural strength in different polymer composite.

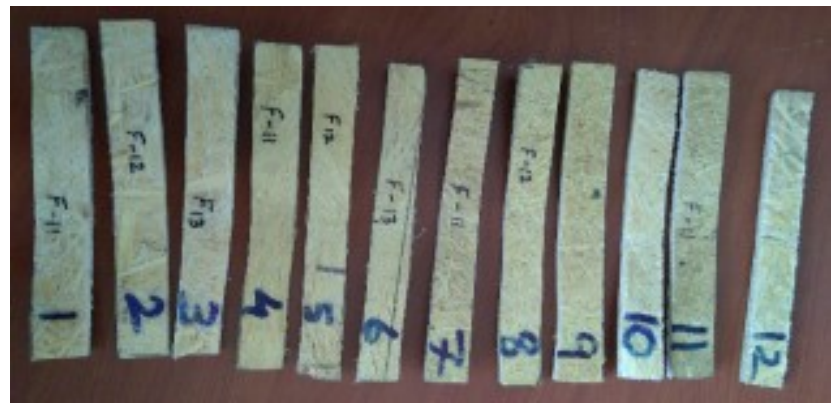

Figure 2: Flexural test specimen

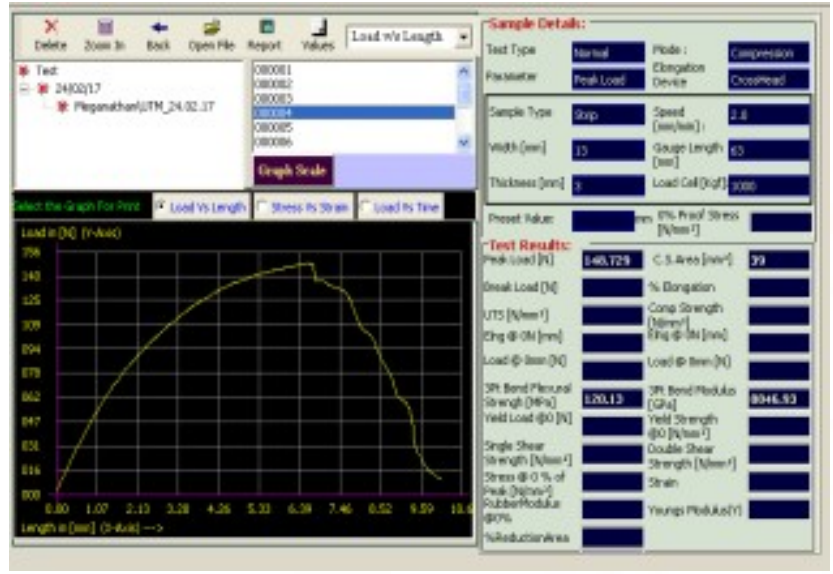

Figure 3.Flexural test output result

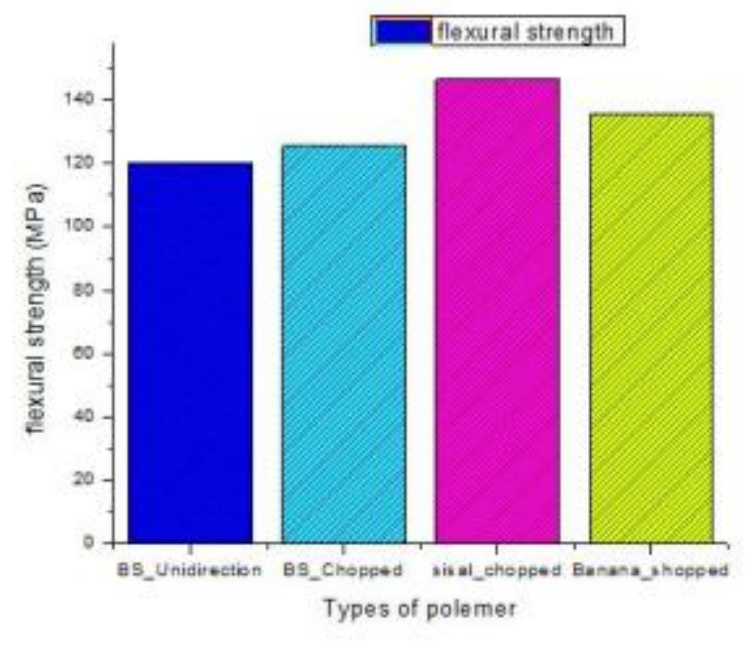

Fig. 4 flexural strength

\subsection{Water Absorption Test}

The ASTM D- 570-98 are using water absorption test. The water absorption method is contacted by two days of immersion in distilled water. To find the dry specimen weight by sing Sartorius ED 224S model because $0.001 \mathrm{~g}$ precision. After the test the specimen are removed from distilled water at the end of the dipping periods. The blotting paper are using to spread the surface water and calculate the wet weight of the specimen. The figure 5 shows the weight percentage of different samples in after testing method. 


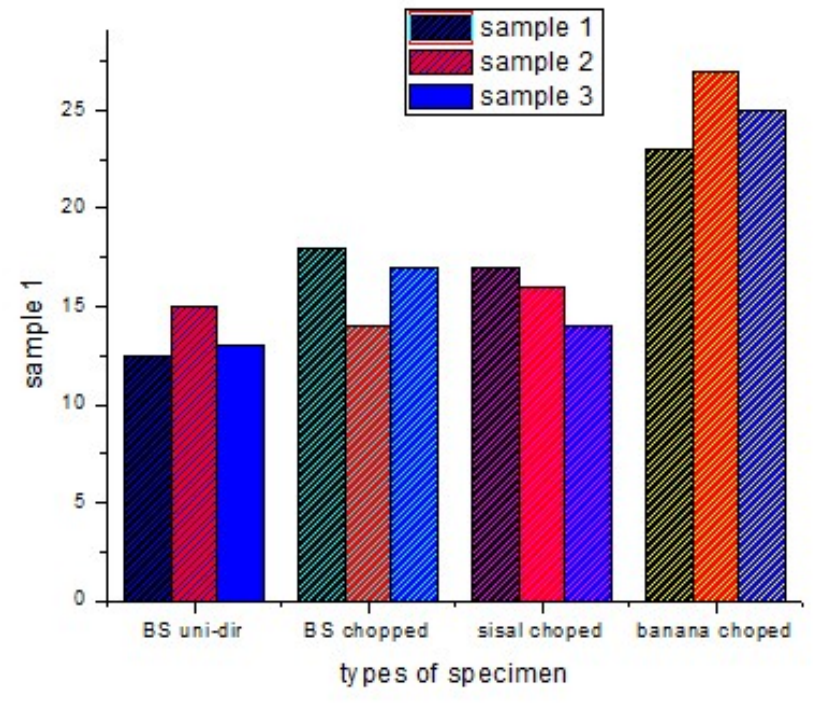

Figure 5: Water absorption test specimens

\subsection{Tensile Test}

The tensile and compressive strength are performed by using ASTM -3039 standard.and experiments are done by UTM universal testing machine. The compressive and tensile load are applied to the specimen and to estimate the tensile strength value. The figure 6 shows the contour plot for tensile strength vale and percentage of bana. The contour plot clear shows the percentage of volume of banana fiber and also to get in the maximum result of tensile strength.

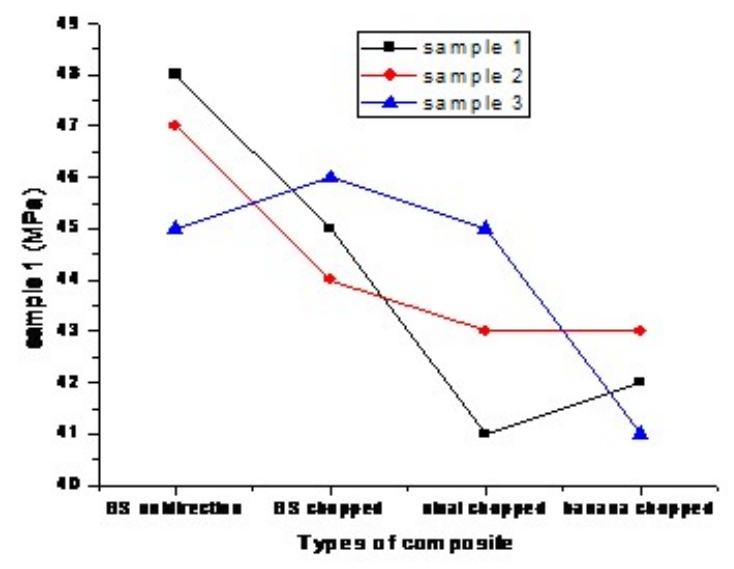

Figure 6: Tensile test results

\subsection{Impact Test}

The different types of polymer composite are performed by impact test such as 1.banana and sisal unidirectional, 2. Banana and sisal chopped, 3. Sisal chopped and 4. Banana chopped. In all types of composite to conduct the impact test as per standard procedure and also find the how many energy are observed by the specimen. The figure 7 clearly shows the variation of impact strength in different composite.

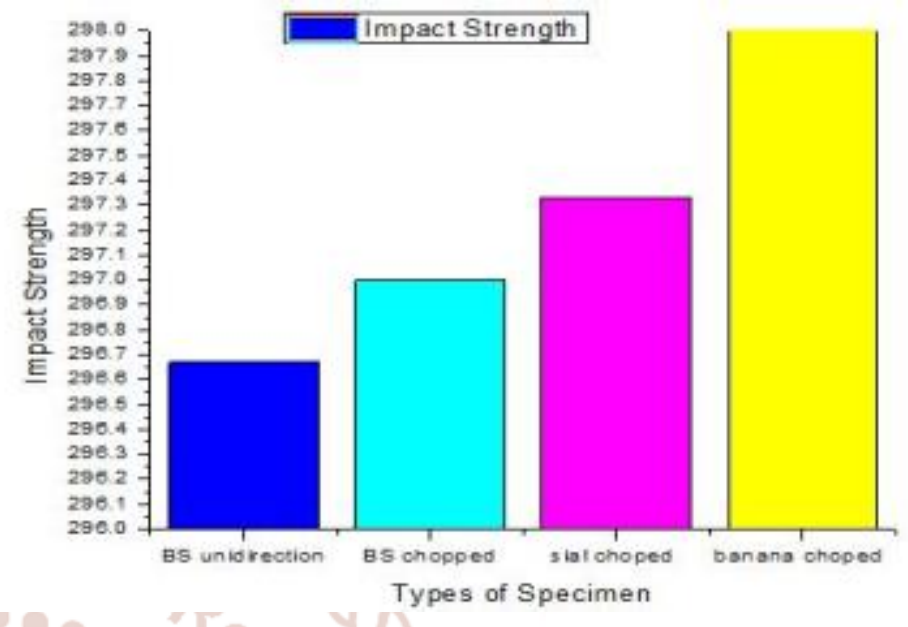

Figure 7 Impact test results

\section{CONCLUSION}

This experimental investigation of mechanical behavior of banana and sisal reinforced epoxy composites leads to the following conclusion

- The mechanical properties will be change with change in composition of Fiber.

- On combination of sisal and banana chopped having higher flexural strength when compare to other chopped banana, chopped sisal and uni banana sisal.

- Chopped banana Fiber individually had the lowest water absorption but low flexural strength so it should be mix with sisal Fiber to obtain the desired strength and mechanical properties.

- Increase in hardener ratio with epoxy resin mechanical properties will change and excessive hardener will lead towards brittleness of composite material.

- In this experiment the length of Fiber are kept constant, if length variation takes place, properties also changes. 
International Journal of Trend in Scientific Research and Development (IJTSRD) ISSN: 2456-6470

\section{REFERENCES}

1. SiakaOluwoleoladele,OluyemiOjodaramola and Solomon FASOOTO(2014) Effect Of Chemical Treatment On The Mechanical Properties Of Sisal FIBER Reinforced Polyester Composites.ISSN 1583-1078

2. Kumaresan, SathishandKarthi (2015), Effect Of FIBER Orientation On Mechanical Properties Of Sisal FIBER Reinforced Epoxy Composites. VOL 18 NO 3 PP 289-294 (2015)

3. Kuruvilla Joseph, Romildo Dias TolêdoFilho, Beena (2014), A Review On Sisal FIBER Reinforced Polymer Composite. V 3,N3,P.367379,1999

4. T.Hariprasad, G.Dharmalingam and P.Praveenraj (2016), Study Of Mechanical Properties Of Banana-coir Hybrid Composite Using Experimental And Fem Techniques.

5. Hemantpatel, prof. Ashishparkhe, Dr P.K. shrama(2016), Vol.4issu.1, Mechanical Behaviors Of Banana And Sisal Hybrid Composites Reinforced With Epoxy Resin.ISSN-23500530(O)ISSN2394-3629(P)

6. Velmurugan, D.vadivel, Int R.Arravind, S.P.Vengatesan, A.Mathiazhagan (2012), Tensile Test Analysis Of Natural FIBER Reinforced Composite.(IJMIE) ISSN.NO.2231-6477

7. C.Chaithanyan, H.Venkatasubramanian, Dr.S.Raghuraman, T.Panneerselvam (2013), Vol.2issue12, Evaluation of Mechanical Properties Of Coir-sisal Reinforced Hybrid Composites Using Isophthalic Polyester Resin. ISSN2319-8753

8. B. M. deAraújo, E.P.Lima, L.H.L.Louro, S.N.Monteiro, PraçaGeneralTibúrcio (2014), Ballistic Performance Of Sisal FIBER Reinforced Epoxy Composite InMultilayeredArmor.

9. Romildo Dias TolêdoFilho, Kuruvilla Joseph, KhosrowGhavami\& George Leslie England (2014), The Use Of Sisal FIBER As Reinforcement In Cement Based Composites. VOL3 N2 P.245-256,1999

10. J. K. D. Santos, R. A. D. Cunha, R. C. T. S. Felipe, R. N. B. Felipe, G. G. Medeiros (2011), Composite Friend Sisal / Polyester Treated In Surface. ISSN-1807-1600

11. N. GargueudedjimN.Allarabeye ,Charlet, J. F. Destrebecq, R. MoutouPitti\& J.-L. Robert (2015), Vol.15 issue 3 version1.0, Mechanical Characteristics OfFIBERPalmyra.ISSN 22494596
12. Pradeep and Edwin Raja Dhas (2016), An international journal (Msej) Vol.2 no.3, Evaluation Of Mechanical Property On Palm/Coir Based Polymer Matrix Composites.

13. SankarIrullappasamy, DurairajRavindran, and Irulappasamy Siva (2016), society of plastic engineers, Wear Mechanisms In Palmyra FruitFiber-reinforced Polymer Composites

14. C. Romão, P. Vieira, J.L. Esteves(2015), Mechanical Characterization Of Sisal Fiber For Reinforcing Of Composite Materials With Several Different Surface Treatments.

15. Zhaoqian Li, Xiaodong Zhou, and Chonghua Pei(2011), Effect Of Sisal FIBER Surface Treatment On Properties Of Sisal FIBER Reinforced PolylactideComposites.DOI $10.1155 \backslash 2011 \backslash 803428$

16. Thiruchitrambalam,A.Alavudeen,A.Athijayamani, N.Venkateshwaran, andA.ElayaPerumal (2015)material physics and mechanics, Improving Mechanical Properties Of Banana/Kenaf Polyester Hybrid Composites Using Sodium Lauryl SulfateTreatment.E-ISSN 0976-3495

17. V.Arumugaprabu, M .Uthayakumar, F.Cardona and MTH. Sultan (2016), Mechanical Characterization Of Coir/Palmyra Waste FIBER Hybrid Composites.DOI 10.1088/1757899X/152/1/012054

18. N.Venkateshwaran $\bigcirc$ and A.Elayaperumal (2013)IJET, Banana FIBER Reinforced Polymer Composites- A Review. VOL 5 NO 5

19. C.Mahesh, B.Kondapanaidu, K.Govindarajulu and V.Balakrishnamurthy (2013) Vol.5, Experimental investigation of thermal and mechanical properties of PalmyraFIBER reinforced polyester composites with and without chemical treatment and also addition of chalk powder.VOL $5 \mathrm{NO} 5$ 2013

20. J.Santhosh, N.Balanarasimman, R.Chandrasekar, S.Raja (2015), Study Of Properties Of Banana FIBER Reinforced Composites. 